\title{
Remote physiological monitoring in livestock: Assessment of stress in transit to improve welfare
}

\section{A Mitchell ${ }^{1}$, P J Kettlewell ${ }^{2}$, M Villarroell ${ }^{3}$, M Farish ${ }^{1}$, E Harper ${ }^{4}$}

${ }^{1}$ SAC, Penicuik, Midlothian, United Kingdom, ${ }^{2}$ ADAS, Boxworth, Cambridge, United Kingdom, ${ }^{3}$ Escuela Técnica Superior de Ingenieros Agronomos, Madrid, Spain, ${ }^{4}$ Consultancy, Bruton, Somerset, United Kingdom

Email:malcolm.mitchell@sac.ac.uk

Introduction Modern intensive livestock production systems may impose a number of potential stressors upon the animals that may compromise welfare, health and productivity. Thus, during livestock transportation the "on-board" thermal microenvironment may pose a major threat to animal welfare and may be associated with reduced production efficiency and mortality (Mitchell and Kettlewell 2008). The quantification of physiological responses in the face of environmental challenges presented by production, handling and transport environments may be used to characterise the extent of physiological stress imposed and when incorporated in to the process of "physiological stress modelling" such data may constitute the basis of definition of acceptable ranges and limits for environmental variables such as temperature and humidity (Mitchell 2005). The transportation thermal environment presents some particular difficulties as it may be continuously changing during a long journey in response to external climatic conditions as well as being influenced by vehicle ventilation and animal metabolic heat and water production. In these circumstances continuous monitoring of the animals physiological responses is required but this is made difficult by the complex nature of vehicle environments and restricted access to the animals under commercial transport conditions and vehicle configurations. Ideally a method for the continuous remote monitoring of meaningful physiological variables or signals is required that does not necessitate the presence of an observer or any human intervention in order to make the measurements. It may be proposed that both radiotelemetry and physiological data logging represent potential methodologies fulfilling these criteria. In the present study both techniques have been employed to monitor and record deep body temperature responses of pigs and lambs to journeys under hot weather conditions typical of those encountered in southern and central Europe in summer

Materials and methods The journeys employed were of 8 hours duration and are typical of those associated with the transportation of animals to slaughter. Four journeys were undertaken with pigs and two with lambs. On each journey up to 180 pigs (mainly gilts) were transported (average body weight $102 \pm 6 \mathrm{~kg}$ ) at a space allowance of $0.52 \mathrm{~m}^{2}$ per animal. For the lambs 600 mixed sex animals (average body weight $22 \pm 2 \mathrm{~kg}$ ) were transported (200 per deck) using a space allowance of $0.15 \mathrm{~m}^{2}$ per animal. The experimental journeys were undertaken in the Spanish province of Aragon in August in daylight between 07:00 and 15:00 with average journey times of 8.1 hours and 7.5 hours for pigs and lambs respectively. A midjourney break (vehicle stationary) of around 30 minutes duration was taken approximately 3 hours in to the journey. In each case a circular route from and back to the farm or collection centre of origin was employed. Temperatures and relative humidities were recorded on each of the three decks of the vehicle and at air inlets and fan outlets where appropriate. Ambient conditions were recorded by sensors mounted on the exterior of the vehicle. For each journey 8 pigs were previously surgically implanted with a radio-telemetry package to continuously record abdominal deep body temperature (DBT) 14 days prior to travel. In preparation for each lamb journey 8 animals were surgically implanted with modified temperature data loggers for continuous recording of intra-peritoneal temperature at least 2 weeks before the journey. Mean DBT values obtained at 1 minute intervals were determined in pre, post-transport and journey periods and were compared with control body temperature (the pre-journey period) by analysis of variance.

Results The average ambient temperature during journeys transporting pigs was $32^{\circ} \mathrm{C}$ and the water vapour density was $9.2 \mathrm{~g} / \mathrm{m}^{3}$. The corresponding values for the journeys involving lambs were $31.4^{\circ} \mathrm{C}$ and $10.4 \mathrm{~g} / \mathrm{m}^{3}$. These mean temperatures are equal to or exceed the EU recommended limits (without tolerances) in current and proposed legislation and may thus be deemed to represent potential heat stress conditions for both species. The associated ambient and "on-board" water vapour densities are representative of relative humidities in the range of approximately $30-45 \%$ and thus indicate relatively "dry" conditions". The patterns of DBT before, during and after typical journeys for pigs and lambs indicate that despite the elevated ambient temperatures during the journey and an apparent associated thermal challenge the DBT values for both pigs and lambs did not increase during the journeys and in fact decreased indicating some cooling in transit (see Table 1). It is proposed that these apparent decreases in core temperature result from convective cooling in the moving vehicle.

Table 1 Mean deep body temperatures during the pre-journey control period and in transit (mean $\pm \mathrm{SD}$ )

\begin{tabular}{lllll}
\hline \hline Journey & $\begin{array}{l}\text { Control } \\
\text { temperature }\left({ }^{\circ} \mathrm{C}\right)\end{array}$ & $\begin{array}{l}\text { body } \\
\text { temperature in transit } \\
\left({ }^{\circ} \mathrm{C}\right)\end{array}$ & $\begin{array}{l}\text { Change } \\
\left({ }^{\circ} \mathrm{C}\right)\end{array}$ & Significance \\
\hline Pigs & $39.2 \pm 0.41$ & $38.9 \pm 0.24$ & -0.3 & $\mathrm{NS}$ \\
Lambs & $39.8 \pm 0.23$ & $39.3 \pm 0.37$ & -0.5 & $\mathrm{P}=0.006$ \\
\hline \hline
\end{tabular}

Conclusions The results demonstrate that continuous monitoring of physiological variables in "real" animal production and transport conditions is an essential tool for assessing physiological stress and welfare and that more detailed physiological information is essential when assessing the effects of the thermal microenvironments in transit in relation to the adequacy and pertinence of current and proposed animal transport welfare legislation.

Acknowledgements This research was financially supported by Defra

\section{References}

Mitchell, MA 2005. In Mechanistic Modelling in Pig and Poultry Production, Eds. R.M. Gous, T.R. Morris, C. Fisher, pp 209-228.

Mitchell, MA, Kettlewell, PJ 2008. Veterinaria Italiana 44, 213-225. 